to 285 , chiefly due to closure of gas works by extension of the grid system of distribution. The 575 visits of inspection included 36 by the Chief Inspector and there were 142 further miscellaneous visits and 64 visits not under the Acts. The dust-testing team from the Department of Scientific and Industrial Research completed during the year 20 months of its three-year contract period and made 28 tests of dust emission from registered premises. The work has shown that circumstances in field work may require substantial modification of procedures laid down in accepted standard methods for dust measurement. Maintenance of operation of plants to prevent discharges of noxious and offensive gases from registered premises was generally satisfactory.

\title{
THE BRITISH COKE RESEARCH ASSOCIATION
}

$\mathrm{T}$ $\mathrm{HE}$ nineteenth annual report of the British Coke Research Association* is noteworthy for the record of continued expansion and progressive research undertaken during the year 1962. One immediate objective has been the direction of attention to the more practical aspects of tho results of research. This has been stimulated by the Association's participation in the Special Assistance to Industry Scheme, sponsored by the Department of Scientific and Industrial Research. The use of films, a fully equipped mobile laboratory and an expansion of the technical liaison and advisory services are now additional means of 'putting over' the great amount of 'know-how' which has been learned during past years about the correct methods of sampling, sample-preparation, physical testing and analysis of coke.

Naturally, with the competitive challonge of alternative fuels and of alternative methods of metallurgical practice, the question of the supply and demand of fuels manufactured from coals must constantly be a matter for vigilance and close examination. In recent years there have been changes in the demand for blast-furnace coke, partly as a result of the reduction in the production of steel. The demand has also fallen for the technical reason that blast furnaces now use less coke per ton of pig iron produced, because of the extension and improvement of sinter practice and the successful application to blast. furnace operation of the injection of fuel oil and of powdered coal. Given, however, a reasonable level of expansion of the national economy, the demand should not change much in coming years. Moreover, it has been concluded that the blast furnace will remain the principal producer of iron in the foroseeable future. While the coke-oven process, with improvements, will continue to be used to meet the demand for blast-furnace coke, there is, however, a possibility of a new process being developed, using cheaper coal and giving a product of uniform shape and size, described as a 'formed coke' which might prove to be more economic in use than the conventional product. Depending on capital and running costs, such a process might be economically competitive with the coke-oven process. The development of a formed-coke process, involving the erection of costly prototypes, would undoubtedly prove to be enormously expensive and might possibly be best pursued by international co-operation. The Russians and the Poles, among others, have devoted much time and money in recent years to this question. It is very satisfactory to learn that the British Coke Research Association is well aware both of the possibilities and the difficulties of adopting such a process, which in the event may best be suited to localities of the world remote from supplies of good coking coal.

A formed-coke process should provide means for the supply of a solid fuel tailored to the future requiroments of the blast furnace; but the Association in fact is mounting a two-headed attack on this difficult question of new typos of fuel for the iron and steel industry. The other possibility which is being investigated is that of influencing the properties and more particularly the size of coke produced in the conventional coke-ovon by controlling

* Nineteenth Annual Report of the British Coke Research Association, 1962. Chesterfield, Derbyshire. the fissuring process during carbonization. Undoubtedly news of developments in both these fields will be awaited with great interest.

Passing to the record of the research achievement, painstaking effort, not always rewarded with equivalent positive result and calling for much detailed experiment, has continued in the general study of additions to the coal blend for carbonization. Examples of the additions in question are coal-tar pitches, petroleum residues, breeze and heavy petroleum oil. Nevertheless, results have arisen that are worth all the effort. Thus in the case of the possible substitution of breeze for a Welsh coal it was found that 3 per cent of fine breeze could replace the most costly component of the blend while providing coke of similar characteristics. Again, in respect of the use of sodium carbonate, the addition of which is known to improve the reactivity of coke for domestic purposos, with a 0.75 per cent addition of this salt before coking not only was the reactivity improved but also the size of the coke and the resistance to impact increased, though the resistance to abrasion fell considerably. Other features of economic importance have been revealed, for example, the determination of the end-point of carbonization, at which the 'soaking' of the charge has reached its optimum in terms of the useful properties developed in the coke.

The provision of means for carrying out coking trials at various ranges of capacity, from a full scale involving a 10 tons charge to as small a quantity as $15 \mathrm{lb}$., has apparently paid off handsomely, for one reads of trials that are necessary in the large oven and others of equal importance being run in the small ones. Further trials of new blends may be run in the large oven, when it has been established in the small ovens that an improvement is likely and that there is no danger of coking pressures large enough to damage the oven.

Since the earliest use of coke for iron production, the demand for metallurgical coke of low sulphur content has persisted and with the progressive exhaustion of the best coking coals the problem of sulphur impurity has renaained of growing importance. More particularly does the difficulty arise in respect of the behaviour of the organic sulphur constituents. The objective is, of course, to discover whether these reactions may ultimately be capable of being controlled. In a very complete examination of the sulphur-carbon complexes to be found in coke, involving the most modern techniques, electronspin resonance measurements among others, it has been concluded tentatively that the surface sulphides make an important contribution to the organic sulphur content of coke and that dehydrogenation by sulphur, and the interaction of sulphur with free radicals present in the coke, contribute to the formation of these complexes during the coking process. Their preservation in the coke seems to depend on their being of stability greater than that of their carbon-oxygen counterparts.

The Applied Studies Laboratory at Chesterfield has been concerned particularly with problems bearing on the thormal behaviour and fissuring of $\operatorname{coke}$, methods of analysis and measurement and the use of oven coke in domestic appliances. The housewife requires a coke of ready combustibility, that is to say, she wants a fuel that 
lights easily and does not go out overnight; accordingly, the questions of coke reactivity and size become the pertinent issue and the metallurgical requirement is the direct contrary of the domestic need. There are, however, situations in which hard coke may suffice for the domestic boiler; they may be defined by suitable experiment.

Progress has been made in the Association's contribution to the provision of cheap and effective methods of liquid-effluent treatment and measures to be taken for the reduction of the emission of smoke, dust and grit at coke ovens. With regard to the former, the Association is supporting, both financially and technically, basic research at the University of Leeds into the biological treatment of gas liquors. Considerable strides have been made in the study of the activated sludge process as applied on a coke-oven plant and of the relative merits of percolating filter processes. It is most interesting to know that these microbiological processes can destroy such undesirable constituents of waste liquors as phenols, cyanides and thio-salts, including thiocyanates, substances which by their poisonous activity can persuade even the scientists to describe some of them as 'devil liquor'. Perhaps even more interesting to the layman is the fact that spoil heaps may be brought into service as percolating filters, and where they also have lagoons these may serve as means of aeration. To bring the rejected refuse of the mine back as an active agent in solving surface effluent problems is indeed to raise slumbering devils to serve mankind. The genus Thiobacillus would appear to give much scope for study, since preliminary results indicate that the organisms reported in the literature are only a fraction of those that exist in Nature. In the matter of atmospheric pollution much has been done in the mitigation of air pollution as the result of the training of cokeoven staff and operatives.

In the associated work of the Northern Coke Research Laboratory the tradition of the devotion to fundamental studies has been sustained. They involve methods of adsorption and microwave spectroscopy. The objectives include the unravelling of the mechanism of the adsorption on carton of oxygen, carbon dioxide and nitrogen under controlled conditions. It is a problem which has challenged the scientific world since the earliest physical chemists applied the methods of chemical kinetics to the basic problems of combustion. The latest methods permit rapid determination of surface area, an essential parameter.

Coke science is not like nuclear science, a subject which makes popular news, but progress which is respected by that section of the scientific world able to appreciate the problems involved is just as worthy of recognition. The Council of the Association, its director, Mr. G. W. Lee, his colleagues and staff are therefore indeed to be congratulated on their achievements. R. J. SARJANT

\section{GEOMETRICAL OPTICS}

$\mathrm{T}$ HE Optical Society of America, at its Rochester meeting in October 1962, awarded the Frederic Ives Medal for distinguished work in optics to Dr. M. J. Herzberger, the head of the geometrical optics department and senior research associate, Research Laboratories, Eastman Kodak Co. The Medal was presented on October 4 by D. L. MacAdam, the president of the Optical Society. A list of some 150 of Dr. Herzberger's publications is given in the June issue of the Journal of the Optical Society of America $(53,659 ; 1963)$ together with the text of his address entitled "Some Recent Ideas in the Field of Geometrical Optics". Dr. Herzberger discussed three particular optical problems on which he had workedthe analysis of optical images, the improvement of achromatic systems, and the algebraic method of designing optical systems. The use of spot diagrams to describe image formation in optical systems is illustrated by application to the analysis of the so-called 'rim-ray curves' and the four-element air-spaced compound triplet, an $f / 5,300-\mathrm{mm}$ 'Tessar'-type lens, is taken as a numerical example. The method will appeal to those who prefer to think in pictures rather than numerically. In 1959 , Dr. Herzberger discovered that it was possible to design lenses, with or without fluorite, which were corrected for colour over a wide range of wave-lengths. The fundamental idea is to consider the refractive index $n$, and not its square, as a characteristic physical quantity, and to utilize the dispersion formula:

$$
n=A+B \lambda+C /\left(\lambda^{2}-\lambda_{0}{ }^{2}\right)+D /\left(\lambda^{2}-\lambda_{0}{ }^{2}\right)^{2}
$$

where $\lambda_{0}$ is a constant which for the wave-length range $365 \mathrm{~m} \mu$ to $1.01 \mu$ and 176 glasses and other transparent substances used in optical design has the value $0 \cdot 168 \mu$. Four data are therefore required to fix the dispersion of an optical substance in the visible region. The data suggested are discussed, and it is shown that two glasses can be used to design an achromat, and if three lens elements made of different glasses are used a superachromat can be designed which is corrected for four colours.

The basic mathematical problems associated with the algebraic design of optical systems, that is without ray tracing, have recently been solved by Dr. Herzberger, and the work remaining consists only of the elementary, but tedious, job of the algebraic solution of certain linear equations with algebraic coefficients and the same nonzero determinant for all orders. In his address Dr. Herzberger explained the meaning of the 'characteristic function' or 'eikonal' and posed the two questions, the answers to which would reduce the designing of lenses to pure mathematics. He then outlined the procedure adopted to determine the focal eikonal to any desired order for an image formation given by a single thick lens with two aspheric surfaces. Dr. Herzberger concluded by saying that he felt confident that it would not be long before the brain achieves a decisive advantage over the computer in the design of optical systems.

\section{FLUOROCARBONS}

\begin{abstract}
THE origin of the organic fluorochemicals industry lay in the refrigeration industry wherein, following several fatal accidents, there arose an urgent demand for a non-inflammable, non-toxic, low boiling-point refrigerant. The pioneers working for General Motors were Drs. McNary, Midgley and Henne, who carried out research on compounds of carbon, fluorine and chlorine, particularly $\mathrm{CCl}_{2} \mathrm{~F}_{2}$ made by the action of $\mathrm{SbF}_{3}$ on carbon tetrachloride. Prof. M. Stacey of the University of Birmingham con-
\end{abstract}

tributes an interesting article on this subject in the Spring 1963 issue of Catalyst, the excellently written and illustrated industrial journal of the Shell Chemical Co., London. "Success was immediate and dramatic", says the author, "and, in 1931, in collaboration with Du Pont, General Motors formed the corporation Kinetic Chemicals which began the commercial production of a range of colourless odourless non-toxic and non-inflammable fluorochlorocarbons which were named the Freons". 